\title{
Interstitial cells of Cajal: A novel hypothesis for the pathophysiology of irritable bowel syndrome
}

\author{
Ahad Eshraghian MD, Hamed Eshraghian MD
}

\begin{abstract}
A Eshraghian, H Eshraghian. Interstitial cells of Cajal: A novel hypothesis for the pathophysiology of irritable bowel syndrome. Can J Gastroenterol 2011;25(5):277-279.
\end{abstract}

Irritable bowl syndrome (IBS) affects a large proportion of the world's population, and accounts for a considerable number of visits to gastroenterologists and general practitioners. Despite its high prevalence, the precise mechanism of IBS has not been identified to date. The interstitial cells of Cajal (ICC) participate in the production of slow waves and the regulation of their propagation through the gastrointestinal system; thus, they are important components of gastrointestinal motility. The present review proposes that ICC play a central role in the pathophysiology of IBS. This hypothesis is based on many links between ICC and currently proposed mechanisms of IBS pathophysiology. It appears that ICC may be involved in almost all of the previously explained pathogenic mechanisms of IBS. If proven, this hypothesis may provide a key to solving the IBS mystery.

Key Words: Gastrointestinal motility; Interstitial cells of Cajal; Irritable bowel syndrome

Since their characterization by Raymond V Cajal (1), three main - functions for the interstitial cells of Cajal (ICC) have been proposed: to act as mechanoreceptors; to mediate enteric neuronal signals to smooth muscle cells; and to pace slow waves and regulate their propagation (2). ICC are present throughout the digestive system, from the esophagus to the anus. These cells express a tyrosine kinase receptor c-Kit - and can be detected by immunochemical techniques (3). Four known subtypes of ICC are present in the myenteric plexus region (ICC-MP), intramuscular region (ICC-IM), deep muscular plexus (ICC-DMP) and at the level of the submucosa (ICC-SMP) (2). Abnormalities in ICC numbers or integrity have been reported in several diseases such as achalasia, infantile hypertrophic pyloric stenosis, chronic intestinal pseudo-obstruction, Hirschsprung's disease, inflammatory bowel diseases and slow transit constipation (2). Irritable bowl syndrome (IBS), characterized by the alteration of bowl habits and abdominal discomfort, is a common functional disorder worldwide. The most important mechanisms described in the process of IBS are gastrointestinal (GI) dysmotility, serotonin (5-HT) dysregulation and visceral hypersensitivity (4). However, there is no well-established mechanism accounting for the pathophysiology of IBS.

\section{HYPOTHESIS}

We hypothesize that ICC play an important role in the pathogenesis of IBS. The present review discusses the evidence supporting this hypothesis and focuses on GI motility, 5-HT and its receptors, nitrergic and cholinergic neurotransmission, inflammation of the GI system and gut hormones.

\section{ICC AND GI MOTILITY}

\section{Generation of slow waves}

The GI system exhibits electrical activity in the form of slow waves and fast activity spikes, which are also known as action potentials.

\author{
Les cellules interstitielles de Cajal : une nouvelle \\ hypothèse pour la physiopathologie du syndrome \\ du côlon irritable
}

Le syndrome du côlon irritable (SCI) touche une forte proportion de la population mondiale et suscite un nombre considérable de consultations chez le gastroentérologue ou le praticien généraliste. Malgré la forte prévalence de SCI, on n'en a pas déterminé le mécanisme précis jusqu'à présent. Les cellules interstitielles de Cajal (CIC) participent à la production d'ondes lentes et à la régulation de leur propagation dans le système gastro-intestinal. Elles constituent donc des éléments importants de la motilité gastro-intestinale. Dans la présente analyse, on postule que les CIC jouent un rôle central dans la physiopathologie du SCI. Cette hypothèse se fonde sur de nombreux liens entre les CIC et les mécanismes de la physiopathologie du SCI proposés actuellement. Il semble que les CIC puissent participer à la quasi-totalité des mécanismes pathogènes du SCI. Si cette hypothèse est démontrée, elle pourrait constituer une clé pour résoudre le mystère du SCI.

ICC-MP and ICC-IM are responsible for the production of slow waves in the stomach and small intestine, while slow waves in the colon mainly originate from ICC-SMP (5). A high incidence of slow-wave electrical activity (6) and an abnormal pattern of slow waves in the form of a tachyarrhythmic pattern and occasional action potentials (7) have been reported in IBS patients. This higher incidence of slow waves in IBS patients may originate from an altered number or integrity of ICC-MP and ICC-IM in the small intestine, and ICC-SMP in the colon.

\begin{abstract}
High-amplitude-propagating contractions
Colonic contraction waves with a pressure of greater than $50 \mathrm{mmHg}$ and propagated more than $10 \mathrm{~cm}$ in normal individuals are defined as high-amplitude-propagating contractions (HAPCs) (8). These contractions are frequently associated with urges for defecation that resemble cramps. Some studies have recently proposed an association between HAPCs and pain episodes in IBS patients. IBS patients with constipation experience drastically fewer HAPCs per $24 \mathrm{~h}$ period. In contrast, an increased number of these contractions are seen in IBS patients with diarrhea (8). ICC in Auerbach's plexus, a subgroup of ICC-MP in the colon, are known to be involved in the production of HAPCs (9). Taken together, another probable association between IBS and ICC is through the production of HAPCs. The number of ICC in Auerbach's plexus are increased in diarrhea-predominant IBS and decreased in constipation-predominant IBS patients.
\end{abstract}

\begin{abstract}
Migratory motor complex
Smooth muscle layers in the stomach, small intestine or colon produce cyclic contractions known as the migratory motor complex (MMC) (10). It propagates through the GI tract and is involved in the propulsion of food materials. A study (11) examining the periodicity of MMC reported that intervals between MMC cycles are
\end{abstract}

Department of Internal Medicine, Shiraz University of Medical Science, Shiraz, Fars province, Iran

Correspondence: Dr Ahad Eshraghian, Department of Internal Medicine, Nemazee Hospital, Shiraz University of Medical Science,

PO Box 71345-1744, Shiraz, Fars province, Iran. Telephone 98-711-6276212, fax 98-711-6276212, e-mail eshraghiana@yahoo.com

Received for publication July 27, 2010. Accepted August 12, 2010 
shorter in diarrhea-predominant IBS patients, and longer in constipationpredominant IBS patients. Previous studies have established the role of ICC-IM in nitric oxide (NO)-dependent neurotransmission. On the other hand, endogenous $\mathrm{NO}$ suppresses MMC frequency and inhibition of $\mathrm{NO}$ synthesis increases the intervals between MMC cycles (12). As a result, a decrease or loss in the number of ICC-IM can diminish NO transmission and subsequently increase MMC frequency and increase the intervals between MMC. Therefore, we conclude that shorter intervals between MMC cycles in diarrhea-predominant IBS patients are secondary to an increase in the number of ICC-IM and a subsequent increase in NO transmission. Longer intervals between MMC cycles in constipation-predominant IBS patients are secondary to a decrease in the number of ICC-IM and a subsequent reduction in $\mathrm{NO}$ transmission.

\section{ICC AND 5-HT}

Another fact to strengthen our hypothesis is the association between 5-HT and IBS, and the new findings regarding the expression of 5-HT receptors on ICC. The role of 5-HT in IBS has been well established in recent years, and drugs targeting 5-HT receptors are used routinely in the treatment of IBS. It has been reported (13) that patients with constipation-predominant IBS have reduced plasma levels of 5-HT, while plasma 5-HT levels are increased in diarrhea-predominant IBS patients. Conversely, recent studies revealed that 5 -HT2B receptors are expressed on ICC, especially ICC-MP and ICC-DMP. There is also recent evidence (14) that activation of the 5 -HT2B receptor through protein kinase $\mathrm{C}$-gamma mediates the proliferation of ICC.

Therefore, elevated levels of 5-HT in diarrhea-predominant IBS patients induces the proliferation of ICC, thereby exacerbating GI dysmotility and other IBS symptoms. The reverse mechanism can be true in IBS patients with constipation.

\section{ICC AND INFLAMMATION}

Inflammatory processes have also been proposed as having a role in the pathophysiology of IBS. Published data from an animal study (15) suggested that inflammation was related to the loss of ICC and alterations of slow waves in the form of reduced slow-wave duration. Ignoring the precise mechanism, the logical trace of ICC is apparent.

\section{CHOLINERGIC AND NITRERGIC NEUROTRANSMISSION IN THE GUT AND ICC}

The predominant role of the noradrenaline system and the increased activity of the dopaminergic inhibitory system is to reduce acetylcholine bioavailability and subsequent reduction in GI contractility. This mechanism was proposed in IBS patients with constipation. In IBS patients with diarrhea, the serotonergic system predominates and can cause inhibition of noradrenaline and the dopaminergic system, increasing the acetylcholine level and propulsive activity (16). Animal studies suggest that chronotropic effects of cholinergic nerve stimulation and acetylcholine release occur via ICC-IM (17). ICC-IM are also required for $\mathrm{NO}$-dependent neurotransmission. As explained previously, the nitrergic system is also involved in IBS through the critical role of $\mathrm{NO}$ in the modulation of MMC. All of these facts suggest a role for ICC in the pathogenesis of IBS via regulation of cholinergic and nitrergic neurotransmission.

\section{ICC AND GUT HORMONES}

Another point discussed here is the interaction between ICC and gut polypeptides. Plasma and sigmoid tissue levels of vasoactive intestinal peptide are increased in IBS patients. A study by Kim et al (18) showed that vasoactive intestinal peptide also inhibits the pacemaker activity of ICC via the NO-cGMP-protein kinase G pathway. ICC-MP are known to express neurokinin 1 receptors and, through them, tachykinins such as neuropeptide Y regulate intestinal motility (19). Both plasma and sigmoid levels of neuropeptide $\mathrm{Y}$ have been reported to be lower in IBS patients, with a greater decrease in diarrhea-predominant
IBS than in constipation-predominant IBS patients (20). Plasma and sigmoid levels of another gut hormone, cholecystokinin, were significantly increased in IBS patients compared with normal controls (20). Data regarding the expression of cholecystokinin receptors on ICC are also available, especially ICC-IM (21). Evidence regarding the associations among gut hormones, ICC and IBS support our hypothesis.

\section{ICC AND VISCERAL HYPERSENSITIVITY}

Visceral hypersensitivity, defined as a reduced threshold of pain and discomfort, is one of the central characteristics in IBS (4). The exact pathogenesis of visceral hypersensitivity has not been fully recognized yet; however, several mechanisms such as inflammation, psychosocial factors and altered sensorimotor function of the gut have been described (22). Purinergic (P2) receptors were determined to play a role in visceral hypersensitivity. To date, two types of $\mathrm{P} 2$ receptors have been characterized: P2X receptors are ATP gated, and P2Y are $\mathrm{G}$ protein-coupled receptors (23). There are also several subtypes of P2 receptors - P2X and P2Y receptors are expressed on ICC in guinea-pig intestine. Thus, the role of ICC in visceral hypersensitivity is highlighted.

\section{CONCLUSION}

IBS is a chronic, relapsing gastrointestinal problem, affecting a considerable percentage of the global population. It has a negative impact on quality of life and imposes huge costs on health care systems. As described, most of the known and central mechanisms of IBS can be associated with different subgroups of ICC. Based on these facts, we hypothesized a role for ICC in the pathophysiology of IBS. Clearly, IBS is a heterogeneous disease, probably involving several pathogenic pathways. We believe that knowing more about ICC may contribute to a better understanding of IBS.

Verifying this hypothesis will create a new area of research not only toward mechanism, but also for new treatment options for IBS and, if proven, is another step forward in understanding the pathogenesis of IBS.

\section{KEY SUMMARY POINTS}

- IBS is a prevalent disease worldwide, but the exact underlying mechanisms are still unclear.

- Different subtypes of ICC are present in the myenteric plexus and intramuscular regions, the deep muscular plexus and at the level of the submucosa.

- A pivotal role for ICC may be considered because these cells are involved in currently described pathogenic mechanisms of IBS including their role in GI motility, the 5-HT system, alterations in cholinergic and nitrergic neurotransmission, inflammation and gut hormone levels.

CONFLICTS OF INTEREST: None to declare.

\section{REFERENCES}

1. Cajal RV. Sur les ganglions et plexus nerveux d'intestin. C R Soc Biol (Paris) 1893;5:217-23.

2. Sarna SK. Are interstitial cells of Cajal plurifunction cells in the gut? Am J Physiol Gastrointest Liver Physiol 2008;294:372-90.

3. Huizinga JD, Thuneberg L, Kluppel M, et al. W/kit gene required for interstitial cells of Cajal and for intestinal pacemaker activity. Nature 1995;373:347-9.

4. Akbar A, Walters JRF, Ghosh S. Visceral hypersensitivity in irritable bowel syndrome: Molecular mechanisms and therapeutic agents. Aliment Pharmacol Ther 2009;30:423-35.

5. Lammers WJ, Stephen B. Origin and propagation of individual slow waves along the intact feline small intestine. Exp Physiol 2008;93:334-46. 
6. Taylor I, Darby C, Hammond P, Basu P. Is there a myoelectrical abnormality in the irritable colon syndrome? Gut 1978;19:391-5.

7. Shafik A, El-Sibal O, Shafik AA, Ahmed I. Electric activity of the colon in irritable bowel syndrome: The 'tachyarrhythmic' electric pattern. J Gastroenterol Hepatol 2004;19:205-10.

8. Chey WY, Jin HO, Lee MH, et al. Colonic motility abnormality in patients with irritable bowel syndrome exhibiting abdominal pain and diarrhea. Am J Gastroenterol 2001;96:1499-506.

9. Pluja L, Alberti E, Fernandez E, et al. Evidence supporting presence of two pacemakers in rat colon. Am J Physiol Gastrointest Liver Physiol 2001;281:255-66.

10. Sarna SK. Cyclic motor activity; migrating motor complex. Gastroenterology 1985;89:894-913.

11. Kellow JE, Gill RC, Wingate DL. Prolonged ambulant recordings of small bowel motility demonstrate abnormalities in the irritable bowel syndrome. Gastroenterology 1990;98:1208-18.

12. Powell AK, Bywater RA. Murine intestinal migrating motor complexes: Longitudinal components. Neurogastroenterol Motil 2003;15:245-56.

13. Dunlop SP, Coleman NS, Blackshaw E, et al. Abnormalities of 5-hydroxytryptamine metabolism in irritable bowel syndrome. Clin Gastroenterol Hepatol 2005;3:349-57.

14. Wouters MM, Roeder JL, Tharayil VS, et al. Protein kinase $\mathrm{C} \gamma$ mediates regulation of proliferation by the serotonin 5 -HT2B receptor. J Biol Chem 2009;284:21177-84.
15. Der T, Bercik P, Donnelly G, et al. Interstitial cells of cajal and inflammation-induced motor dysfunction in the mouse small intestine. Gastroenterology 2000;119:1590-9.

16. Crowell MD. The role of serotonin in the pathophysiology of irritable bowel syndrome. Am J Manag Care 2001;7(8 Suppl):S252-60.

17. Forrest AS, Ördög T, Sanders KM. Neural regulation of slow-wave frequency in the murine gastric antrum. Am J Physiol Gastrointest Liver Physiol 2006;290:486-95.

18. Kim BJ, Lee JH, Jun JY, et al. Vasoactive intestinal polypeptide inhibits pacemaker activity via the nitric oxide-cGMP-protein kinase $G$ pathway in the interstitial cells of Cajal of the murine small intestine. Mol Cell 2006;30:337-42.

19. Shimizu Y, Matsuyama H, Shiina T, et al. Tachykinins and their functions in the gastrointestinal tract. Cell Mol Life Sci 2008;65:295-311.

20. Zhang H, Yan Y, Shi R, et al. Correlation of gut hormones with irritable bowel syndrome. Digestion 2008;78(2-3):72-6.

21. Patterson LM, Zheng H, Ward SM, Berthoud HR.

Immunohistochemical identification of cholecystokinin A receptors on interstitial cells of Cajal, smooth muscle, and enteric neurons in rat pylorus. Cell Tissue Res 2001;305:11-23.

22. Azpiroz F, Bouin M, Camilleri M, et al. Mechanisms of hypersensitivity in IBS and functional disorders. Neurogastroenterol Motil 2007;19(1 Suppl):62-88.

23. Burnstock B. The journey to establish purinergic signalling in the gut. Neurogastroenterol Motil 2008;20(Suppl 1):8-19. 


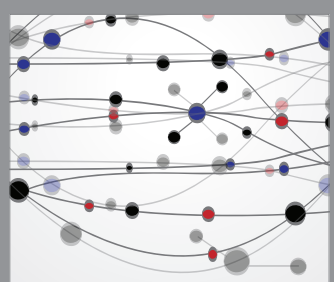

The Scientific World Journal
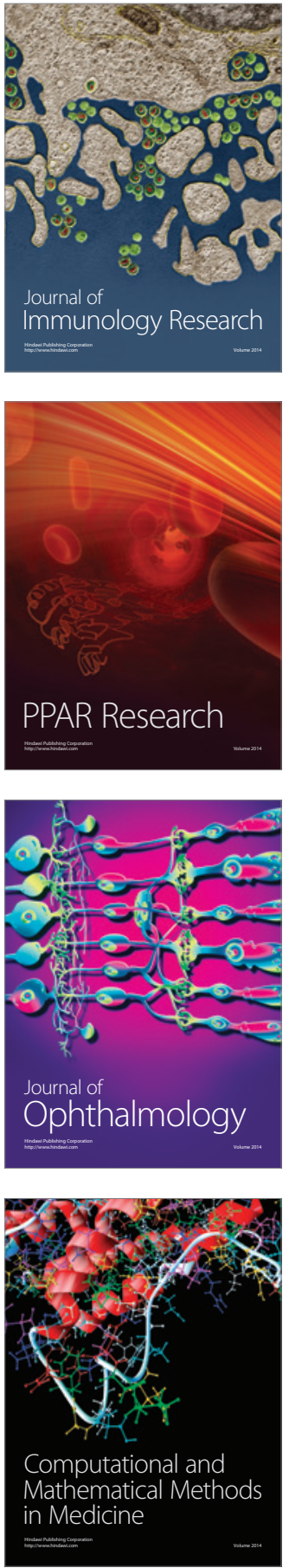

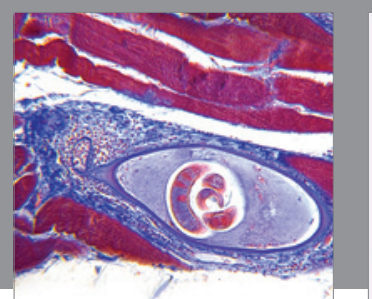

Gastroenterology Research and Practice

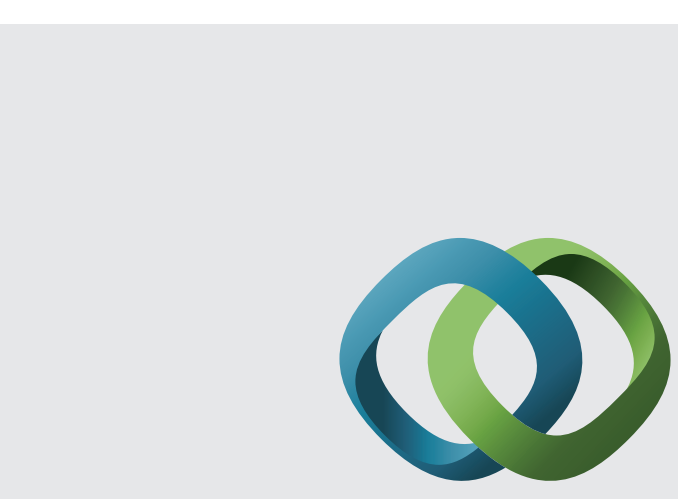

\section{Hindawi}

Submit your manuscripts at

http://www.hindawi.com
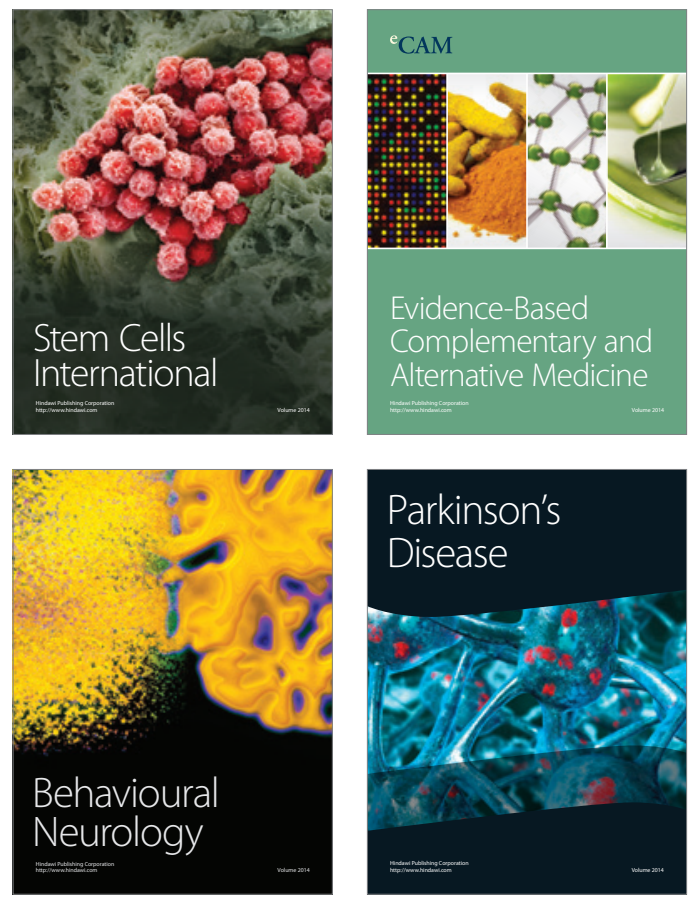
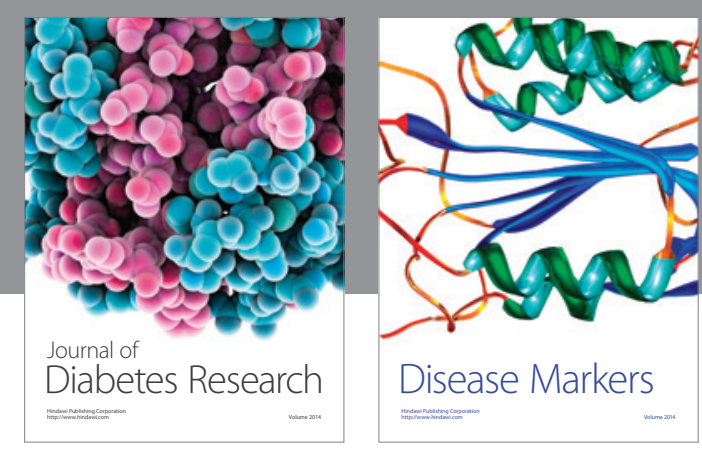

Disease Markers
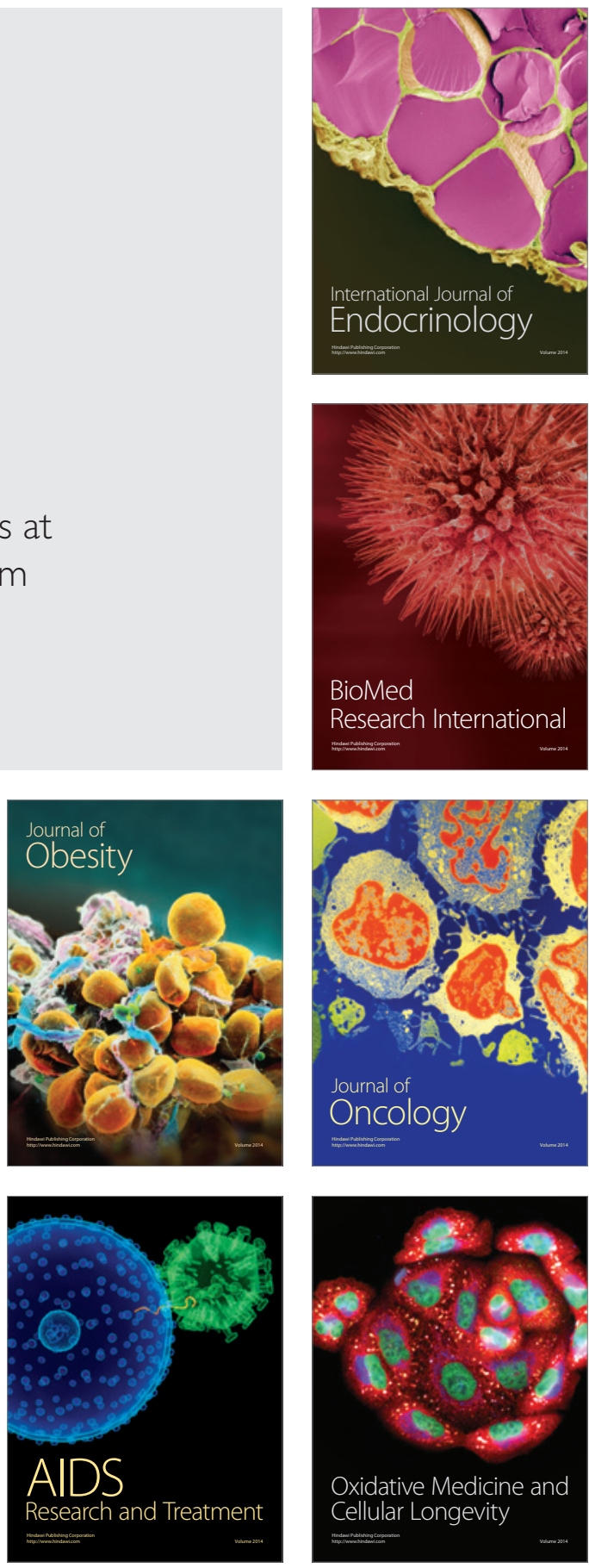